\title{
The haustorial host-parasite interface in rust-infected bean leaves after high-pressure freezing
}

\author{
G. M. Knauf $\dagger$, K. Welter $\dagger$, M. Müller + and K. Mendgen $† \S$ \\ † Universität Konstanz, Fakultät für Biologie, Lehrstuhl für Phylopathologie, D-7750 Konstanz, Federal Republic of \\ Germany; + Laboratorium für EM I, Institut für Zellbiologie, ETH Zürich, CH-9092 Zürich, Switzerland
}

(Accepted for publication October 1988)

\begin{abstract}
The haustorial fine structure of the bean rust fungus, Uromyces appendiculatus var. appendiculatus, was studied within the cells of its host, Phaseolus vulgaris. Results were obtained after high-pressure freezing and subsequent freeze-substitution or freeze-fracturing. Good preservation of leaf tissue after freeze-substitution needed cryoprotection with $8 \%$ methanol. For freeze-fracturing, no chemical treatment was applied. In addition to the organelles which are generally found in fungi after cryo-fixation, tubular-vesicular complexes were found in the cytoplasm. Both techniques revealed an extrahaustorial matrix of even width, surrounding the haustorial body. The extrahaustorial membrane was not undulated, and the side facing the plant cytoplasm was lined with a delicate fringe of well-stained material. The extrahaustorial membrane was nearly devoid of intramembrane particles. The host plasma membrane in infected tissue, especially the protoplasmic face, had fewer intramembrane particles than those in uninfected tissue. The haustorial plasma membrane contained many intramembrane particles.
\end{abstract}

\section{INTRODUCTION}

A prerequisite for understanding host-parasite interactions is an adequate fine structure preservation of the interface between the two organisms. However, during conventional fixation with glutaraldehyde and osmic acid, a number of artifacts are introduced in samples $[7,19,24]$ and similar artifacts may also be expected at the haustorial host-parasite interface. This may be the reason why there is so much speculation about the organization of this area $[9,21]$.

Cryo-fixation seems to reduce such artifacts considerably [8]. However, convincing ultrastructural qualities have been observed only in specimens with a thickness of a few micrometers. These specimens include mainly fungal structures grown in vitro [see 12]. Parasitic structures, such as hyphae or haustoria, have been studied only when they were growing below the cuticle, within the epidermis of the host plants $[6,11]$. In contrast, the bean rust fungus colonizes the deeper, parenchymal tissue of its host and, therefore, satisfactory preservation of ultrastructural detail with cryo-fixation is found only after high-pressure freezing (HPF), which allows samples of up to $600 \mu \mathrm{m}$

$\S$ 'To whom correspondence should be addressed.

Abbreviations used in text: EF, exoplasmic fracture face; EMA, extrahaustorial matrix; EME, extrahaustorial membrane; HPF, high-pressure freezing; IMP, intramembrane particle; PF, protoplasmic fracture face; TVG, tubular-vesicular complex. 
thickness to be frozen $[25,26]$. Subsequent freeze-substitution always includes mild chemical fixation. In contrast, for freeze-fracturing the samples are not treated with chemical fixatives and therefore may closely reveal the natural state of a cell. $A$ s replicas cannot reveal all cellular details, we employ freeze-substitution and freezefracturing for comparison. Here, we present a description of haustorial fine structure with improved preservation of cellular membranes and cytoplasmic details.

\section{MATERIALS AND METHODS}

\section{Plant cultivation and inoculation}

The fungus, Uromyces appendiculatus var. appendiculatus, was cultivated on susceptible bean plants (Phaseolus vulgaris L., cv. Fori). The plants, grown in soil, were kept under a $16 \mathrm{~h}$ photoperiod (approximately $120 \mu \mathrm{mol} \mathrm{m} \mathrm{m}^{-2} \mathrm{~s}^{-1}$ ), approximately $70 \% \mathrm{RH}$ and $18-20^{\circ} \mathrm{C}$. Fourteen-day-old primary leaves were inoculated with freshly collected uredospores and incubated for $24 \mathrm{~h}$ in $\operatorname{dim}$ light at $18{ }^{\circ} \mathrm{C}$ and under $100 \% \mathrm{RH}$.

\section{Cryo-fixation and freeze substitution}

Infected areas ( $2 \mathrm{~mm}$ diameter) were excised from leaves 4 to 6 days after inoculation. These samples were vacuum-infiltrated, either with tap water or with distilled water containing $8 \%(\mathrm{v} / \mathrm{v})$ methanol at room temperature, in order to remove the air from the intercellular space. When methanol was used, the solution around the samples was renewed after infiltration in order to maintain the original concentration of methanol. Samples remained in the methanol solution for 5-10 min. Single samples were then placed in specially-made aluminium holders (one side has a hollow of $0.3 \mathrm{~mm}$ depth for the sample, and the other is flat) and immediately frozen at high pressure using the Balzers HPM 010 apparatus [25, 26]. Frozen samples were stored in liquid nitrogen until further processing.

The medium for freeze substitution (1.5 ml per specimen) consisted of 2 or $4 \%$ osmium tetroxide in acetone which had been dried by calcium chloride. Samples were freeze-substituted in this medium during successive periods of $8 \mathrm{~h}$ each at $-90^{\circ} \mathrm{C}$, $-60^{\circ} \mathrm{C}$ and $-30^{\circ} \mathrm{C}$ [27] in the Balzers FSU 010 apparatus. Subsequently, the temperature was raised to approximately $0^{\circ} \mathrm{C}$ within $30 \mathrm{~min}$ and the samples were washed in dry acetone for another $30 \mathrm{~min}$.

Samples were infiltrated with an Epon/Araldite mixture in the following stages: $30 \%$ resin in acetone at $+4{ }^{\circ} \mathrm{C}$ for up to $7 \mathrm{~h} ; 70 \%$ and $100 \%$ resin at $+8{ }^{\circ} \mathrm{C}$ for up to $20 \mathrm{~h}$ in each; and $100 \%$ resin at $18{ }^{\circ} \mathrm{C}$ for approximately $12 \mathrm{~h}$. Samples were then transferred to fresh resin and polymerized at $60^{\circ} \mathrm{C}$ for $10 \mathrm{~h}$.

Ultrathin sections were placed on pioloform-coated (Wacker Chemie, München) single hole grids and were stained with $3 \%$ aqueous uranyl acetate and lead citrate [30] for 20 and $2.5 \mathrm{~min}$, respectively. Grids were examined with either a Siemens Elmiskop IA or a Zeiss EM 10C electron microscope operated at $80 \mathrm{kV}$.

\section{Cryo-fixation and freeze-fracturing}

Prior to freezing, leaf segments bearing eight-day-old infections were vacuuminfiltrated with tap water at room temperature in order to remove the air from 
the intercellular space. Samples of approximately $1 \mathrm{~mm}^{2}$ were sandwiched with a drop of tap water between two gold support platelets $(3 \mathrm{~mm}$ diameter) (Balzers, Liechtenstein). The upper platelet was covered with egg lecithin to ensure that it could be removed later without destroying the sample. Freezing was carried out as described above.

Fracturing and replication was carried out with a Balzers BAF 300 freeze-etch device and followed standard procedures [17].

Replicas were cleaned at room temperature in $12 \%$ alcoholic $\mathrm{KOH}$ for $4 \mathrm{~h}, 70 \%$ sulphuric acid for at least $24 \mathrm{~h}$, and $0 \cdot 25 \mathrm{~m}$ chromic acid for $1 \mathrm{~h}$ [29]. The replicas were mounted on pioloform-coated copper grids (50 mesh) and examined with a Zeiss EM $10 \mathrm{C}$ electron microscope operated at $80 \mathrm{kV}$. The terminology according to Branton [1] was used to describe the exposed faces of the membranes. The direction of shadowing is indicated by an arrowhead on each micrograph.

For quantitative analysis of the intramembrane particles (IMPs), plasma membranes of both uninfected and infected plant tissue and of the extrahaustorial membrane (EME) were examined. From each membrane, five images $(\times 200000)$ of the exoplasmic fracture face $(\mathrm{EF})$ and the protoplasmic fracture face $(\mathrm{PF})$ were chosen, and the number of IMPs in each membrane face $\left(0.25 \mu \mathrm{m}^{2}\right.$ per sample $)$ was counted with an MOP - Videoplan (Fa. Kontron, München) and expressed as IMPs per $\mu \mathrm{m}^{2}$. Significant differences in the data were tested using the F-test of Fisher and the student's $t$-test.

\section{RESULTS}

\section{Freeze substitution}

Most samples which had been infiltrated with tap water before freezing disintegrated during freeze-substitution or showed extensive ice damage. Only a few specimens exhibited adequate fine structure. Cryo-protection with $8 \%$ methanol prevented disintegration and reduced ice crystal formation considerably. Therefore, this method of cryo-protection was used routinely. Micrographs from samples infiltrated with tap water are included for comparison [Figs 3(c) and 4(b)].

At the site of penetration into the host cell, the haustorial mother cell wall of $U$. appendiculatus was thickened and closely attached to the plant cell wall [Fig. 1 (a)]. The neck band extended from the fungal plasma membrane to the extrahaustorial membrane (EME), spanning the fungal cell wall [Fig. 1 (b)]. All membranes were smooth and followed closely the contours of walls and organelles [Fig. 1 (a) and (b)].

$A$ dikaryotic haustorium is shown in Fig. 2 (a). In addition to the organelles generally found in haustoria, two types of tubular-vesicular complexes (TVC) were observed. TVC 1 was found frequently. The large complexes consisted of tubules and vesicles with slightly electron-opaque contents [Fig. 3 (a)]. TVCs of type 1 sometimes showed interconnections with the endoplasmic reticulum [Fig. 3 (a) and (c). In contrast, TVC 2 was very small, was found only occasionally, and was not interconnected with other organelles [Fig. 3 (b)]. Treatment with methanol did not influence the fine structure of either type of TVC as demonstrated for TVC 1 in Fig. 3 (c).

The extrahaustorial matrix (EMA) was slightly thicker than the haustorial cell wall, 

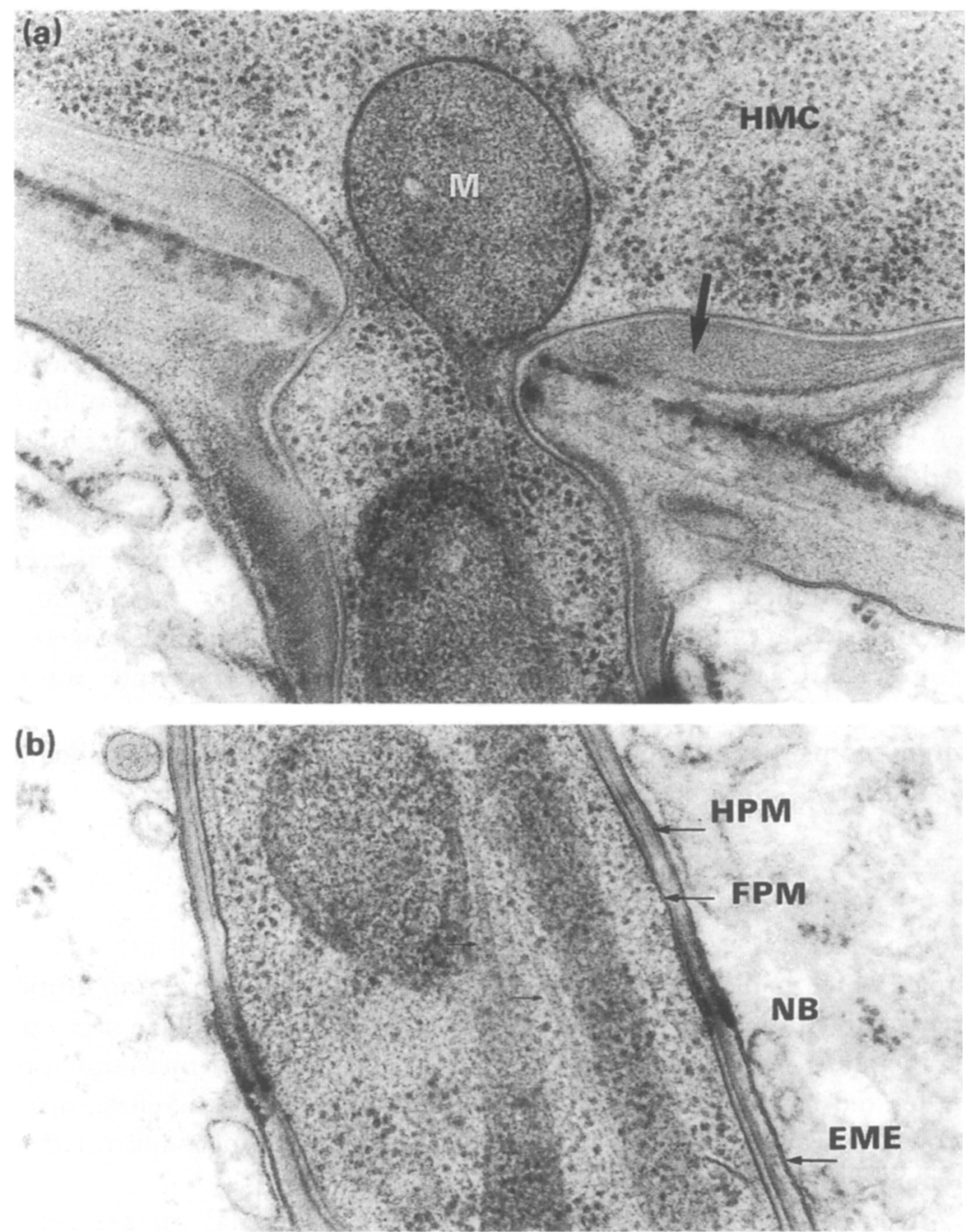

FIG. 1. (a) At the site of penetration into the host cell, the haustorial mother cell (HMC) wall is thickened (arrow). The membranes follow the contours of the walls and organelles closely. $\mathbf{M}$, mitochondrion. $\times 60000$. (b) The neck band (NB) extends from the fungal plasma membrane (FPM) to the EME, spanning the fungal cell wall. The EME is as smooth as the host plasma membrane (HPM). microtubule (arrows) $\times 60000$.

irrespective of haustorial size [Figs 2 (a), 3 (a) and 4 (a)], and was difficult to distinguish from the fungal wall because both structures tended to merge [Figs 2 (a), 3 (a) and 4 (a)]. The EME was smooth, uniformly distant from the haustorial plasma membrane [Figs 2 (a), 3 (a) and 4 (a)] and intensely stained. The face adjacent to the

FIG. 2. (a) A dikaryotic haustorium of $U$. appendiculatus. The most obvious organelle is 'TVG 1 . Plasma membrane (FPM) and EME are smooth, and the EME is lined by a delicate fringe of electron-opaque material (large arrows). The EMA has evenly stained contents. The host tonoplast $(\mathrm{T})$ is undulated by ice crystal formation in the vacuole. $\times 36000$. (b) 'The haustorial cytoplasm shows mitochondria (M), endoplasmic reticulum (ER) and TVG. CW, cell wall; FPM, fungal plasma membrane. $\times 26000$. 
(a)
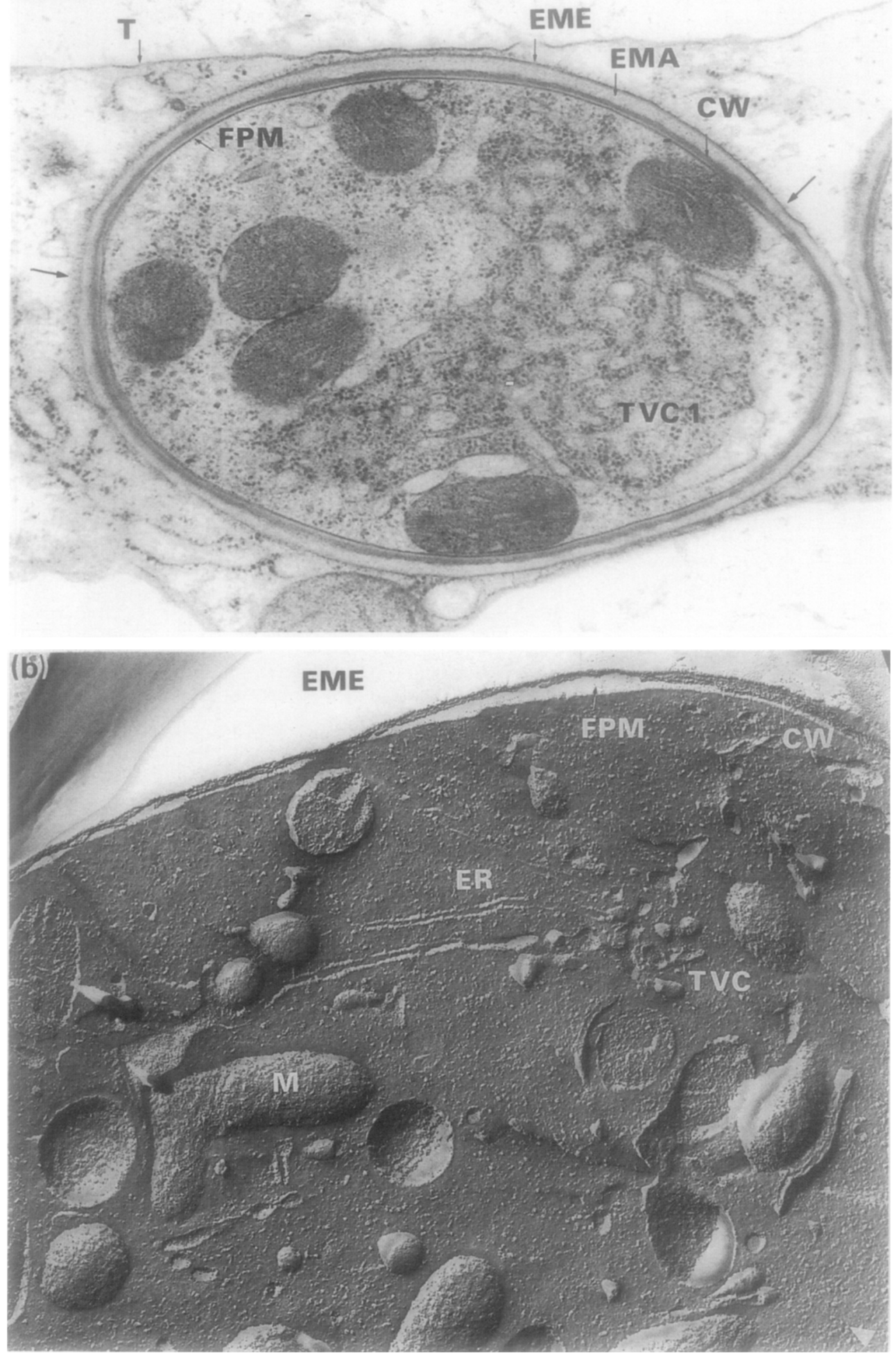

Fig. 2 a-b. For legend see opposite. 

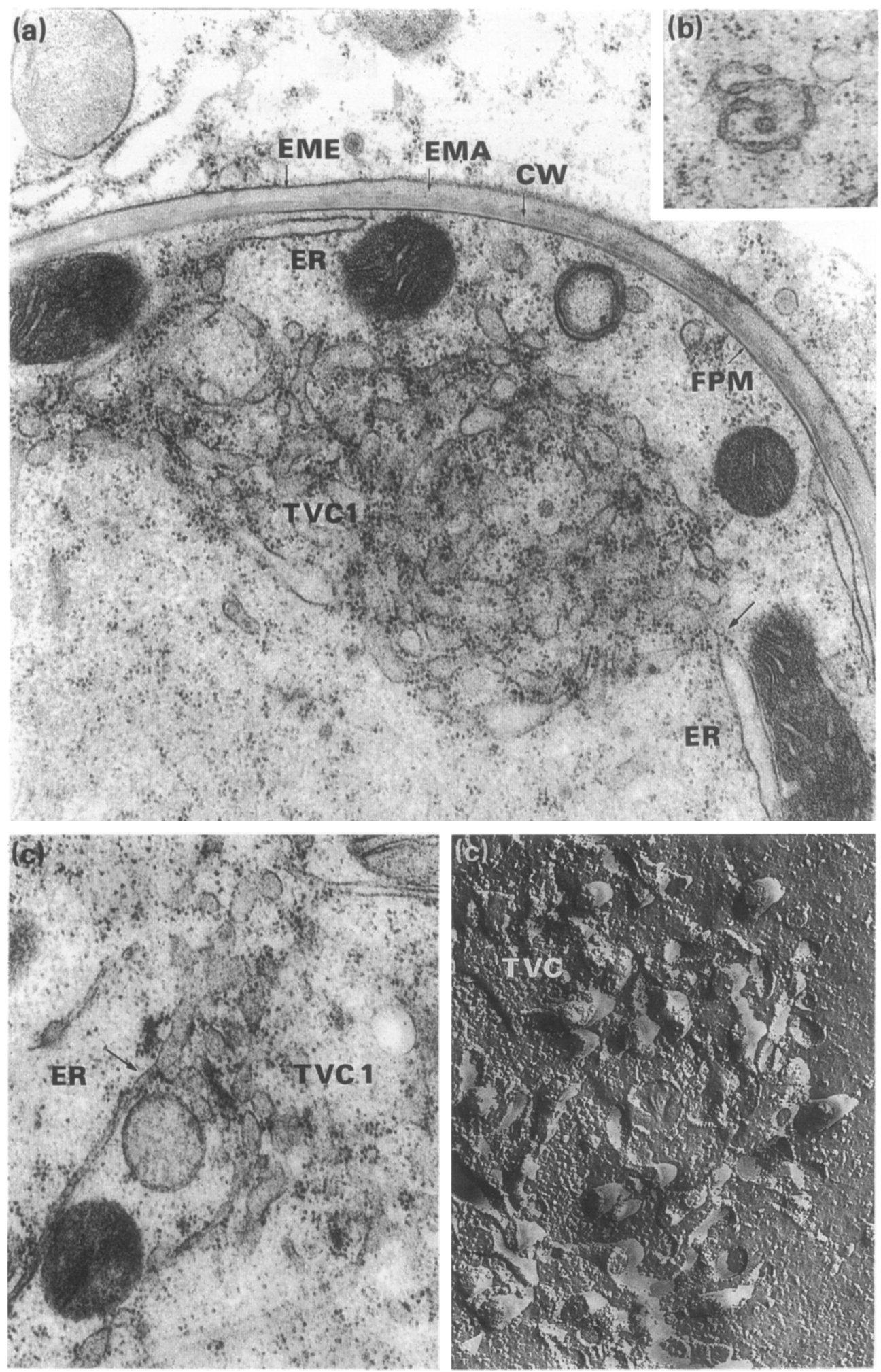

FI(; $3 a-c$. For legend sec opposite. 
plant cytoplasm was generally lined by a delicate fringe of electron-opaque material [Figs 2 (a), 3 (a) and 4 (a)]. Water-infiltrated samples exhibited the same features as those infiltrated with methanol solution, except that the fringe at the EME was less electron-opaque and was thus more difficult to recognize [Fig. 4 (b)].

\section{Freeze-fracturing}

Morphological features similar to those in freeze-substituted material were found after freeze-fracture, which does not involve treatment of the samples with any chemical. Most TVCs were composed of tubules, or cisternae, and vesicles, which appeared to be unconnected [Figs 2 (b) and 3 (d)]. Depending on the plane of fracture, membranes of TVCs exhibited numerous intramembrane particles (IMP) [Fig. 3 (d)]. TVCs could be distinguished by their shape from the straight and narrow cisternae of the endoplasmic reticulum [Fig. 2 (b)]. The TVCs were randomly distributed and, judged from their size, correspond to the TVC 1 observed after freeze-substitution. Structures corresponding to TVC 2 were not recognized.

In freeze-etch replicas it was difficult to distinguish the EMA from the haustorial wall because there was no bordering line between the two structures [Figs 2 (b) and 4 (b)].

The PF (protoplasmic face) and the EF (exoplasmic face) of the host plant plasma membranes were evenly studded with IMPs. EF and PF of the plant plasma membranes were characterized by different numbers of IMPs (Table 1). In infected host tissue the PF contained three times as many particles as the EF [Table 1, Fig. 5 (a) and (b)]. In contrast, uninfected tissue plasma membranes had many more particles, with the ratio PF/EF of 7:1 [Table 1, Fig. 5 (c) and (d)]. This was based on a significantly different number of particles in the PFs only, whereas the EFs showed no significant difference. IMPs were found in the EME only very occasionally [Table 1, Fig. 5 (e)]. Usually, the PF of the EME was exposed. The haustorial plasma membrane was also densely decorated with IMPs [Fig. 4 (b)], but they were not taken for evalulation of the IMP-distribution as the plane of fracture followed the haustorial plasma membranes only rarely.

\section{DISCUSSION}

Compared with results using conventional techniques [see 21], high-pressure freezing (HPF) has improved the preservation of ultrastructural detail in rust haustoria. Our results are comparable to those obtained after dip-freezing [see 12] or slam-freezing $[6]$. This is indicated by smooth membranes which followed cell walls and organelles closely and by the densely stained fungal cytoplasm. It was necessary to add methanol to the infiltration fluid prior to HPF for subsequent freeze-substitution. In contrast,

FIG. 3. (a) TVC 1 in a dikaryotic haustorium. The contents of the TVG 1 are of medium electron opacity. Interconnections with the endoplasmic reticulum (ER) are apparent (large arrow). $\times 40000$. CW, cell wall; FPM, fungal plasma membrane. (b) TVC 2 is very small. $\times 60000$. (c) Small TVC 1 in a sample not treated with methanol. As in cryoprotected samples, the contents are of medium electron opacity, and there is an interconnection with the endoplasmic reticulum (ER) (arrow). $\times 40000$. (d) The TVC consists of tubules or cisternae and vesicular structures. TVC membranes bear IMPs. $\times 40000$. 

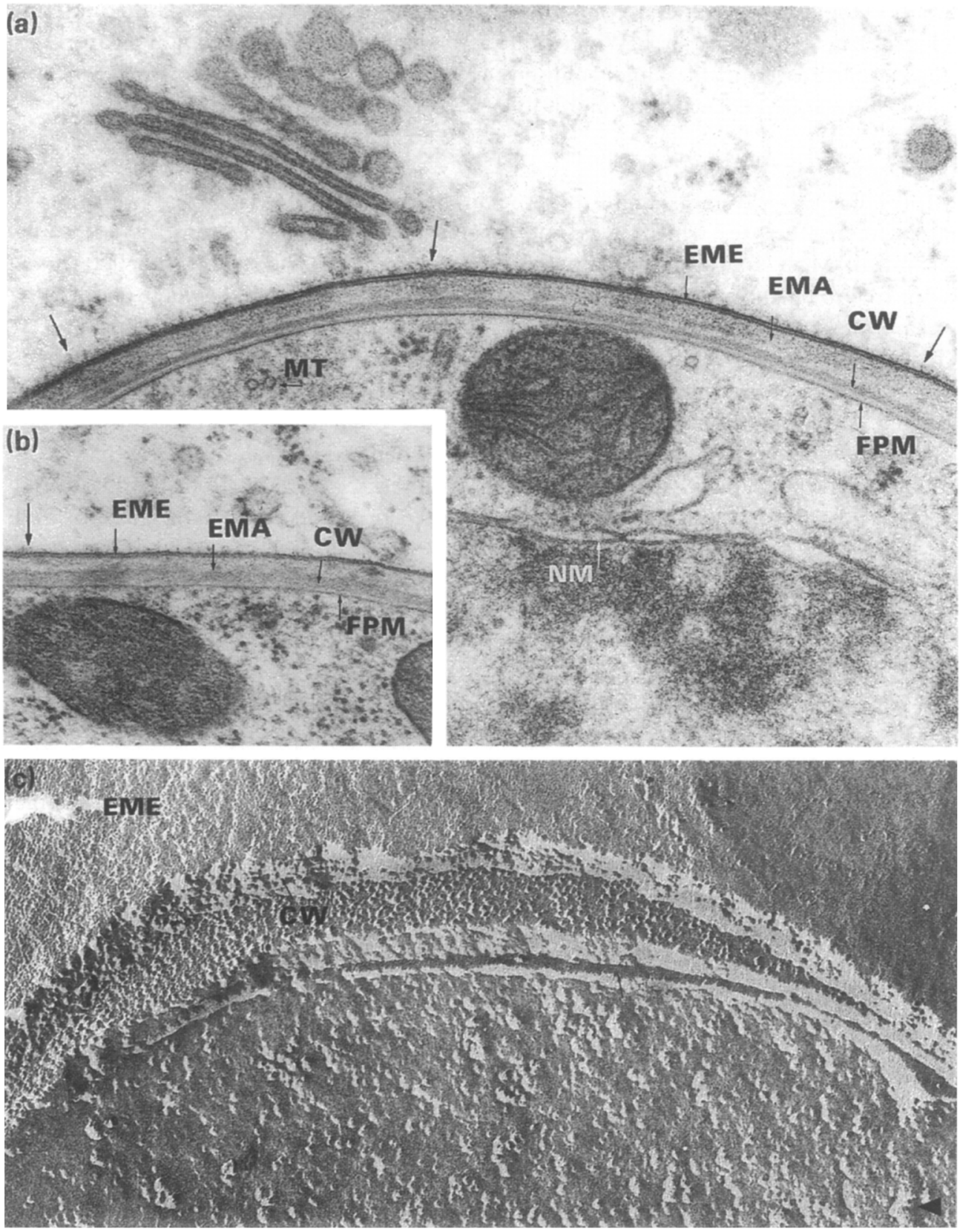

FIG. 4. (a) Interface between the dikaryotic haustorium and the host cell. The EMA is of even electron opacity and it is approximately twice as thick as the haustorial cell wall (CW). Both structures, the haustorial wall (CW) and the EMA, tend to merge. The EME is stained intensely. The side facing the host cytoplasm is lined by a delicate fringe of electron-dense material (large arrows). FPM, fungal plasma membrane; NM, nuclear membrane; MT, microtubulc. $\times 75000$.

(b) The haustorial interface in a sample not treated with methanol exhibits the same features as in cryoprotected samples. $\times 50000$. (c) The smooth EME exhibits only very few IMPs. It is difficult to distinguish the EMA and the cell wall (CW). The fungal plasma membrane (FPM) is studded with IMPs and follows the cell wall closely. Small arrow: haustorial tonoplast. $\times 72000$. 
TABLE 1

Average number of IMPs in $1 \mu^{2}$ areas of the $P$-and $E$-fracture faces of plasma membranes in uninfected (HPM, uninf.) and infected (HPM, inf.) bean tissue and the EME

Fracture face

Membrane

PF

$\mathrm{EF}$

\begin{tabular}{lcc}
\hline HPM, uninf. & $1411 \pm 148^{\mathrm{a}}$ & $205 \pm 21^{\mathrm{b}}$ \\
HPM, inf. & $538 \pm 195^{\mathrm{c}}$ & $180 \pm 65^{\mathrm{b}}$ \\
EME & $30 \pm 25^{\mathrm{d}}$ & $*$ \\
\hline
\end{tabular}

a, b,c, dSignificant differences at a level of $P<0.05$ are indicated by different letters in superscript.

*The number of EFs was too low for statistical analysis.
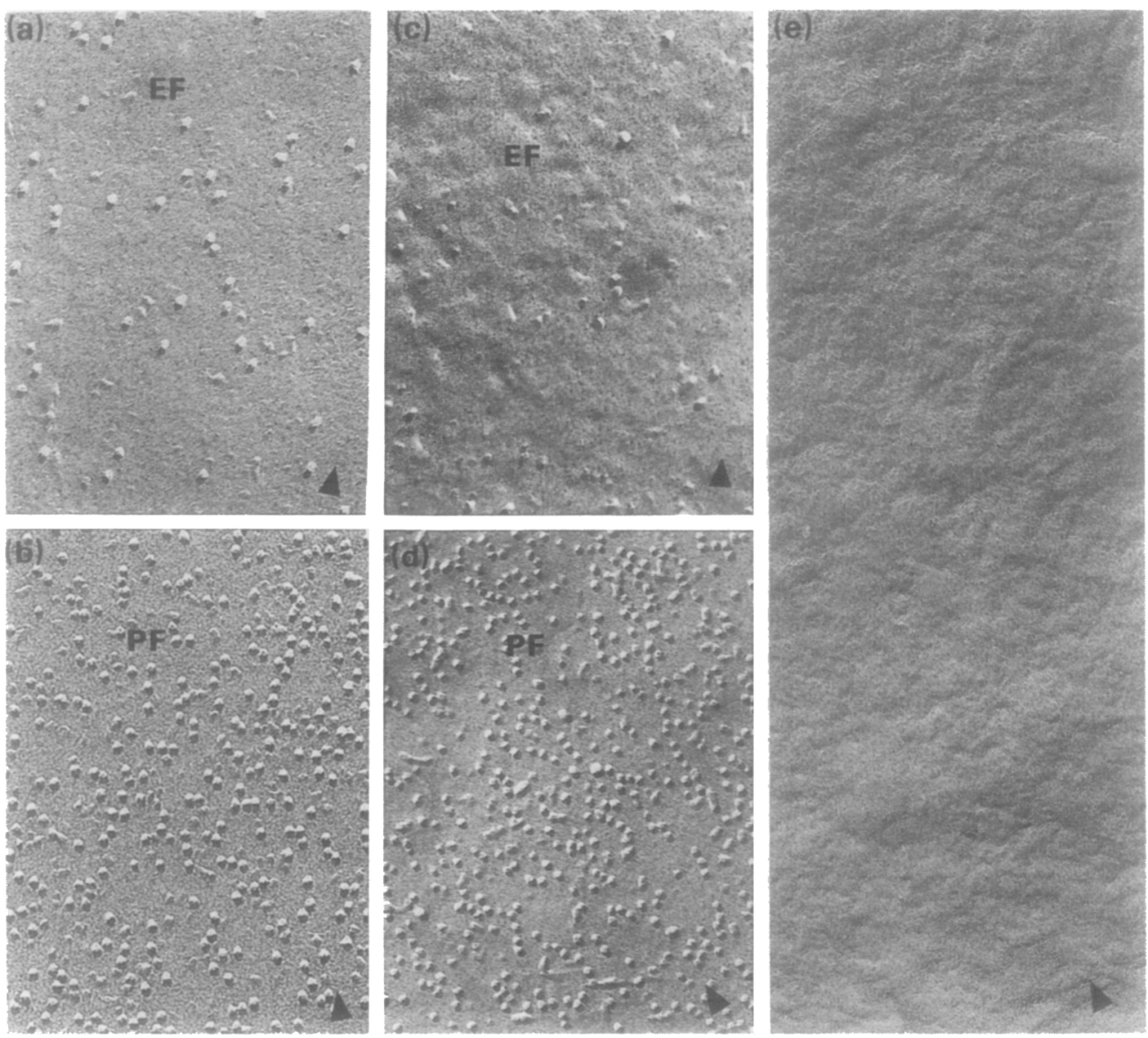

Fig. 5. EF (a) and PF (b) of a plasma membrane in infected bean tissue can be differentiated by the density of the IMPs. $\times 100000 . \mathrm{EF}$ (c) and PF (d) of the plasma membrane in uninfected bean tissue. $\times 100000$. (e) The extrahaustorial membrane is smooth and does not exhibit any IMPs. $\times 100000$. 
the application of cryoprotectants was not necessary for freeze-fracturing because the samples remained frozen during further processing. However, our results do indicate that methanol treatment had no deleterious effect on the fine structure of the samples, in agreement with earlier observations of intercellular hyphae [35].

Haustoria contained most of the organelles which have been found in germ tubes and hyphae of the bean rust fungus after cryofixation and freeze-substitution [14, 35]. However, the highly decorated multivesicular bodies previously described in germ tubes and hyphae $[15,21,34]$ were not observed in bean rust haustoria in this study. This is the first observation of TVCs in haustoria of of $U$. appendiculatus; presumably, they disintegrate during conventional fixation. Structures similar to TVC 1 have been described for conidiospores and haustoria of Erysiphe spp independently of the method of fixation $[6,22]$. On the basis of their shape and size we assume that the TVC 1 in freeze-substituted samples corresponds to the TVC in freeze-fractured replicas. It seems that TVC 1 has some role in the secretion of fungal material [18]. This material may consist of wall constituents or molecules that influence the host-parasite relationship [23]. TVC 2 is morphologically similar to the presumptive Golgi bodies described in cryo-fixed samples of germ tubes of the bean rust fungus and other fungi $[6,13-16,28]$. We think that the TVCs belong to the endomembranous system of the bean rust fungus. Cytochemical studies are now in progress to characterize these morphologically distinct structures by their contents.

There has been much speculation concerning the existence and origin of the extrahaustorial matrix (EMA). Conventional fixation might artificially enlarge the EMA and cause undulation of the extrahaustorial membrane (EME) $[2,3,9,21]$. The detection of different polysaccharides or glycoproteins within the matrix of Puccinia spp. $[4,5]$ indicate that the EMA is a real structure. It appears to be modified during conventional fixation. After HPF, the matrix appears as an even zone surrounding the haustorial body. Similar results have been reported for haustoria of Puccinia coronata after HPF [31].

In earlier studies it has been shown that the EME has properties different from those of the plasma membrane of the host cell, although it is continuous with it [21]. Compared with the plasma membrane, the EME has a different affinity to some cytochemical stains [4, 9, 20], lacks ATPase activity [33], and has a reduced sterol content [10]. After HPF, the EME stained more intensely with the conventional fixation stains than did other membranes, and it displayed a fringe of material on its host cytoplasmic face. Furthermore, no IMPs were found within this membrane, in agreement with the results of Littlefield \& Bracker [20] who used conventional fixation followed by freeze-fracturing. The IMPs are regarded as membrane-intercalated or membrane-bound proteins [33, 34]. IMP-deficiency generally indicates low protein content and hence suggests a less active membrane. Surprisingly, the PF of the plasma membranes in uninfected plant tissue had nearly three times as many particles as the corresponding fracture face in infected tissue. The reduction in number of IMPs in plasma membranes in infected tissue and their absence in the EME may be specific results of the rust infection. However, we cannot explain the physiological meaning of these results. Isolation and characterization of these membranes may help to improve our understanding of the host-parasite interface.

We thank Dr M. A. Stumpf for critically reading the manuscript. 


\section{REFERENCES}

1. Branton, D., Bullivant, S., Gilula, N. B, Karnovsxy, M.J., Moor, H., Mühletaler, K., Northcote, D. H., Packer, L., Satir, B., Satir, P., Speth, V., Staehelin, L. A., Steere, R. L. \& Wernstein, R. S. (1975). Freeze-etching nomenclature. Science 190, 54-56.

2. Bushnell, W. R. (1972). Physiology of fungal haustoria. Annual Review of Phytopathology 10, 151-176.

3. Carling, D. E., White, J. A. \& Brown, M. F. (1977). The influence of fixation procedure on the ultrastructure of host-endophyte interface of vesicular-arbuscular mycorrhizae. Canadian Journal of Botany 55, 48-51.

4. Chong, J., Harder, D. E. \& Rohringer, R. (1981). Ontogeny of mono- and dicaryotic rust haustoria: cytochemical and ultrastructural studies. Phytopathology 71, 975-983.

5. Chong, J., Harder, D. E. \& Rohringer, R. (1986). Cytochemical studies on Puccinia graminis $\mathrm{f}$. sp. tritici in a compatible wheat host. II. Haustorium mother cell walls at the host cell penetration site, haustorial walls and the extrahaustorial matrix. Canadian Journal Botany 64, 2561-2575.

6. DAнмEN, H. \& Новот, J. A. (1986). Ultrastructural analysis of Erysiphe graminis haustoria and subcuticular stroma of Venturia inaequalis using cyrosubstitution. Protoplasma 131, 92-102.

7. DeEtz, J. S. \& Behrman, E. J. (1981). Reaction of osmium reagents with amino acids and proteins. Reactivity of amino acid residues and peptide bond cleavage. International Journal of Peptide and Protein Research 17, 495-500.

8. Gilkey, J. C. \& Staehelin, L. A. (1986). Advances in ultrarapid freezing for the preservation of cellular ultrastructure. Journal of Electron Microscopy Technique 3, 177-210.

9. Harder, D. E. \& Chong, J. (1984). Structure and physiology of haustoria. In The Cereal Rusts, volume 1, Ed. by W. R. Bushnell \& A. P. Roelfs, pp. 431-476. Academic Press, Orlando.

10. Harder, D. E. \& Mendgen, K. (1982). Filipin-sterol complexes in bean rust- and oat crown rustfungal/plant interactions: freeze-etch electron microscopy. Protoplasma 112, 46-54.

11. Hippe, S. (1985). Ultrastructure of haustoria of Erysiphe graminis f. sp. hordei preserved by freezesubstitution. Protoplasma 129, 52-61.

12. Hосн, H. C. (1986). Freeze-substitution of fungi. In Vltrastructure Techniques for Microorganisms, Ed. by H. C. Aldrich \& W. J. Todd, pp. 183-212. Plenum, New York.

13. Hoch, H. C. \& Howard, R. J. (1980). Ultrastructure of freeze-substituted hyphae of the basidiomycete Laetisaria arvalis. Protoplasma 103, 281-297.

14. Hoch, H. C. \& Staples, R. C. (1983). Ultrastructural organization of the non-differentiated uredospore germling of Uromyces phaseoli variety typica. Mycologia 75, 795-824.

15. Howard, R.J. (1981). Ultrastructural analysis of hyphal tip cell growth in fungi: Spitzenkörper, cytoskeleton and endomembranes after freeze-substitution. Journal of Cell Science 48, 89-103.

16. Howard, R. J. \& AIsT, J. R. (1979). Hyphal tip cell ultrastructure of the fungus Fusarium: improved preservation by freeze-substitution. Journal of Ultrastructure Research 66, 224-234.

17. Hudson, C. S., Rash, J. E. \& Graham, W. F. (1979). Introduction to sample preparation for freeze fracture. In Freeze Fracture: Methods, Artifacts, and Interpretations, Ed. by J. E. Rash \& C. S. Hudson, pp. 1-10. Raven Press, New York.

18. Knauf, G. \& Mendgen, K. (1988). Secretion systems and membrane-associated structures in rust fungi after high pressure freezing and freeze-fracturing. Biology of the Cell 64, 363-370.

19. LEE, R. M. K. W. (1984). A critical appraisal of the effects of fixation, dehydration and embedding on cell volume. In The Science of Biological Specimen Preparation for Microscopy and Microanalysis Proceedings of the 2nd Pfefferkorn Conference, Ed. by J.-P. Revel, T. Barnard \& G. H. Haggis, pp. 61-70. AMF O'Hare, Chicago, IL.

20. Littlefield, L. J. \& Bracker, C. E. (1972). Ultrastructural specialization at the host-pathogen

21. Littlefield, L. J. \& Heath, M. C. (1979). Ultrastructure of Rust Fungi. Academic Press, New York.

22. Martin, M. \& Gay, J. L. (1983). Ultrastructure of conidium development in Erysiphe pisi. Canadian Journal Botany 61, 2472-2495.

23. Mendgen, K., Schneider, A., Sterk, M. \& Fink, W. (1988). The differentiation of infection structures as a result of recognition events between some biotrophic parasites and their hosts. Journal of Phytopaihology 123, 259-272.

24. Mersey, B. \& MaGully, M. E. (1978). Monitoring the course of fixation of plant cells. Fournal of Microscopy 114, 49-76.

25. Moor, H. (1987). Theory and practice of high-pressure freezing. In Cryotechniques in Biological Electron Microscopy, Ed. by R. A. Steinbrecht \& K. Zierold, pp. 175-191. Springer-Verlag, Berlin.

26. Müller, M. \& MoOR, H. (1984). Cyrofixation of thick specimens by high pressure freezing. In The Science of Biological Specimen Preparation for Microscopy and Microanalysis - Proceedings of the 2nd Pfefferkorn Conference, Ed. by J.-P. Revel, T. Barnard \& G. H. Haggis, pp. 131-138. AMF O'Hare, Chicago, Il. 
27. Müller, M., Marti, T. \& Kriz, S. (1980). Improved structural preservation by freeze substitution. In Proceedings of the 7th European Congress on Electron Microscopy, The Hague, Ed. by P. Brederoo \& W. De Priester, 2, 720-721, European Congress on EM Foundation, Leiden, The Netherlands.

28. Newhouse, J. R., Hoch, H. C. \& MacDonald, W. L. (1983). The ultrastructure of Endothia parasitica. Comparison of a virulent with a hypovirulent isolate. Canadian Journal of Botany 61, 389-399.

29. Platt-Aloia, K. A. \& Thomson, W. W. (1982). Freeze fracture of intact plant tissues. Stain Technology 57, 327-334.

30. Reynolds, E. S. (1963). The use of lead citrate at high $\mathrm{pH}$ as an electron-opaque stain for electron microscopy. Journal of Cell Biology 17, 208-212.

31. Schneider, A., Müller, M. \& Mendgen, K. (1985). Ultrastructure of the rust fungal/host interface processed by rapid freezing and freeze-substitution. European Journal of Cell Biology, Supplement 10, 65.

32. Smarda, J. (1988). Colicin $\mathbf{K}$ decreases the density of intramembrane particles (IMP) in the cell membrane of Escherichia coli. Journal of General Microbiology 134, 1283-1288.

33. Spencer-Philipps, P. T. N. \& Gay, J. L. (1981). Domains of ATPase in plasma membranes and transport through infected plant cells. New Phytologist 89, 393-400.

34. Verkleij, A. J. \& VervergaerT, P. H. J. T. (1978). Freeze-fracture morphology of biological membranes. Biochimica et Biophysica Acta 515, 303-327.

35. Welter, K., Müller, M. \& Mendgen, K. (1988). The hyphae of Uromyces appendiculatus within the leaf tissue after high-pressure freezing and freeze substitution. Protoplasma 147, 91-99. 